\title{
Atmospheric Dispersion Analysis for Expected Radiation Dose due to Normal Operation of RSG-GAS and RDE Reactors
}

\author{
P.M. Udiyani $i^{1 *}$, S. Kuntjoro ${ }^{1}$, G.R. Sunaryo ${ }^{1}$ and H. Susiati ${ }^{2}$ \\ ${ }^{I}$ Center for Nuclear Reactor Technology and Safety, National Nuclear Energy Agency, \\ Puspiptek Area, Serpong, Tangerang Selatan 15310, Indonesia \\ ${ }^{2}$ Center for Nuclear Energy System Assessment, National Nuclear Energy Agency, \\ Jl. Kuningan Barat, Mampang Prapatan, Jakarta 12710, Indonesia
}

\section{ARTICLE INFO}

Article history:

Received 17 November 2016

Received in revised form 22 March 2018

Accepted 5 April 2018

\section{Keywords:}

Radiation dose

Normal operation

$\mathrm{RDE}$ reactor

RSG reactor

Atmospheric dispersion

\begin{abstract}
A B S T R A C T
BATAN is planning to build an experimental power reactor, the RDE, to complement the RSG-GAS reactor that is already operating in the Serpong Nuclear Zone (KNS). The experimental power reactor is an HTGR (high-temperature gas-cooled reactor) with $10 \mathrm{MWt}$ power, while the RSG-GAS is a pool-type water-cooled reactor with $30 \mathrm{MWt}$ power. According to standard regulatory practices, under normal operating conditions of the plant, radiological assessment of atmospheric releases to the environment and assessment of public exposures are considered essential. The purpose of this study is to estimate the dose acceptance in Serpong Nuclear Zone (KNS) after operate the RDE operates in KNS-2. To assess the doses, the PC-CREAM 08 computer code was used. It uses a standard Gaussian plume dispersion model and composes a suite of models and data for estimation of the radiological impact assessments of routine and continual discharges from a nuclear reactor. The input data include sourceterm from the RDE and the RSG-GAS, a stack the height of $60 \mathrm{~m}$ annual radionuclides release, meteorological data from the Serpong local meteorological station, and agricultural products data from Serpong site. Results show that the highest individual dose in the area around KNS for adults is $6.16 \times 10^{-3} \mathrm{mSv} / \mathrm{y}$ in the $\mathrm{S}$ (South) direction and $300 \mathrm{~m}$ distance from the stack of RSG. The highest collective dose around KNS within $3 \mathrm{~km}$ radius is $6.37 \times 10^{-3} \mathrm{man}-\mathrm{Sv} / \mathrm{yr}$. The results show that the radiological impact of the KNS on the critical groups of public and the individual effective doses satisfy the limits given by the Nuclear Regulatory Agency of Indonesia (BAPETEN). The operation of RDE in KNS-2 does not add significantly to acceptance radiation dose in the environment in KNS. It can also be concluded that the estimated effective doses are lower than the dose constraint of $0.3 \mathrm{mSv} / \mathrm{y}$ associated with this plant.
\end{abstract}

\section{INTRODUCTION}

The Serpong Nuclear Zone (known as Kawasan Nuklir Serpong, KNS, in Indonesian) is a nuclear installation of BATAN. It is divided into KNS-1 and KNS-2. The Serpong Nuclear Zone-1 (KNS-1) consists of the G.A. Siwabessy Multipurpose Reactor (RSG-GAS, Reaktor Serba Guna G.A. Siwabessy in Indonesian)) and its support installations such as Radioactive Waste

\footnotetext{
*Corresponding author.

E-mail address: pmade-u@batan.go.id

DOI: https://doi.org/10.17146/aij.2018.878
}

Management, Radioisotopes and Radiopharmaceuticals, Nuclear Fuel, and Nuclear Reactor Technology and Safety installations and the installation for Nucleaer Engineering. The operation of nuclear installations in the KNS-1 releases radionuclides to the environment, mostly from the RSG-GAS. The RSG-GAS is a research reactor with a maximum power of $30 \mathrm{MWt}$ operating since August 18, 1987. The existing studies on the radiological impacts of RSG-GAS on the public under normal operation are limited to those reported in the RSG-GAS Safety Analysis Report [1]. 
BATAN is planning to build an experimental power reactor, the RDE (Reaktor Daya Eksperimental, Experimental Power Reactor) in the KNS-2. The RDE is planned to be a $10-\mathrm{MWt}$ HTGR [2]. The high-temperature gas-cooled reactor (HTGR) is advanced reactor concept. The plant's design uses basic high-temperature gas-cooled reactor (HTGR) features of ceramic fuel, helium coolant, and graphite moderator [3,4]. The operation of $\mathrm{RDE}$ is expected to impact the environmental radioactivity at overall KNS. Research on environmental radioactivity in KNS-1 due to RSG-GAS reactor operation under normal condition alone has been done, whereas the research on environmental radioactivity due to the operation of both the RSG-GAS in KNS-1 and the RDE in KNS-2 (two reactors in KNS) has not been undertaken. The effect of two reactors in one nuclear site need to be studied. This study aims to find out how much safety level of doses received around KNS site caused by two reactor operating simultaneously.

The objective of this research is to conduct an Expected Radiation Dose analysis to ensure the safety level of radiation doses under normal operating conditions in the KNS due to having the RSG-GAS in KNS-1 and RDE in KNS-2 operating simultaneously. The term "dose" used in this paper refers the sum of the annual external and internal effective doses. The term "total dose" refers to the sum of all the pathways and all nuclides dispersed in the environment. Collective dose is calculated from the dose received and the population in a particular area. Calculations for dose assessment for the RSG-GAS and the RDE reactors at KNS under normal operating conditions were done using PC-CREAM 08 computer program. This code simulates the distribution of radionuclides in the environment due to the normally-operating reactor. Inputs required by this code are radionuclide sourceterm, population distribution around the site (KNS), and hourly meteorological data for the year. The results are individual and collective doses for the population surrounding the KNS.

\section{EXPERIMENTAL METHODS}

The approach followed in conducting the assessment in this paper was based on atmospheric dispersion calculation [5-9] as shown in Fig. 1. The calculation used PC-CREAM 08. The software package needs inputs on sourceterm, meteorological data, population distribution, agricultural and livestock products, and local products consumption. The data on RSG sourceterm was obtained from
RSG SAR reports [1], while for RDE, it is obtained from calculations. All data input besides sourceterm is obtained from KNS based on data input.

Sources term releases will enter the human body through various pathways, depending on the type and behavior of nuclides as well as meteorological and environmental conditions. Means by which the sourceterm, meteorological data, and population data to be used as input for PC-CREAM 08 are produced is summarized in Fig. 1 and will be explained in subsequent subsections.

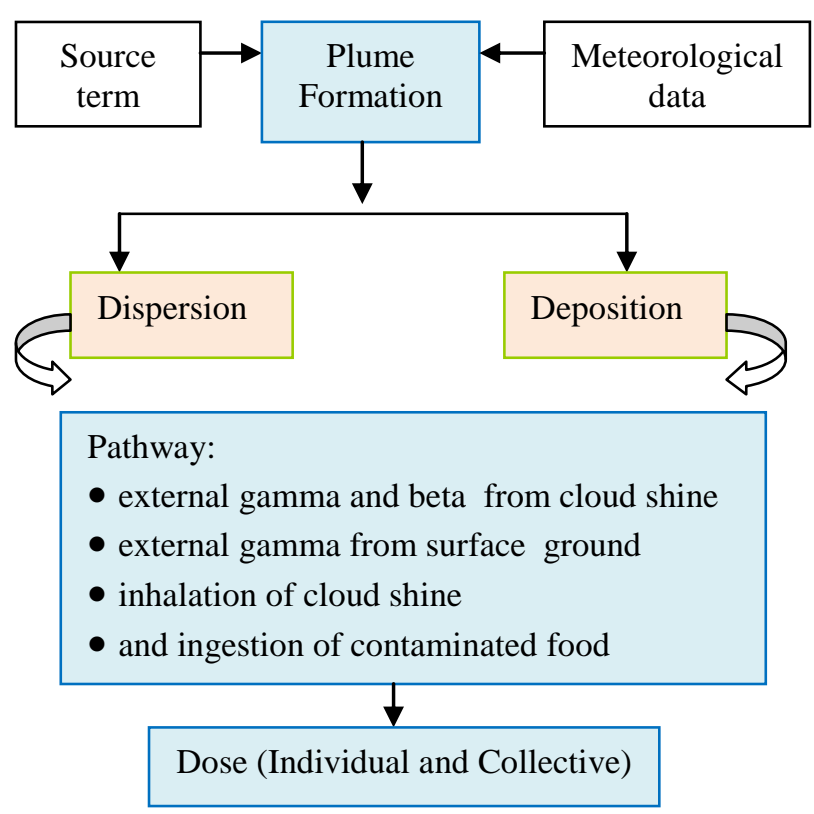

Fig. 1. Methodology approach of radiation dose calculation.

\section{Sourceterm calculation}

Fission products are released from HTGR following the radionuclide transport mechanisms. The release mechanisms includes fuel, core, building ventilation, helium purification, gaseous radioactive waste system, and neutron activation of air circulating through the reactor cavity cooling system (RCCS) [2,10-13]. Radioactive gases accumulate within the waste gas vacuum tank and are compressed by diaphragm compressor. Surge tanks retain these gases for 30 days to allow for radioactive decay before release to the environment $[12,13]$.

In the calculation of reactor inventory and sourceterm, the radionuclides to be analyzed are divided into groups of radionuclides, namely tritium $\left({ }^{3} \mathrm{H}\right)$, noble gases $(\mathrm{Kr}$ and $\mathrm{Xe})$, halogens (I), Sr, Cs, and $\mathrm{Ag}$. Sourceterm was calculated based on reactor inventory. The estimation of radionuclide inventory in the reactor core needs data on the type, power, 
and operation duration of the reactor. The result of inventory calculation is presented in Table 1 . The data used for the inventory calculation was based on a reactor geometry similar to HTR-10 [14] with differences on burnup data input. In this calculation, maximum burnup data was used, while in HTR-10 calculation, average burnup data was used.

Table 1. Design parameters of the RDE [14]

\begin{tabular}{clc}
\hline No. & \multicolumn{1}{c}{ Parameter } & Value \\
\hline 1 & Reactor thermal power (MWt) & 10 \\
2 & Helium coolant pressure (MPa) & 3.0 \\
3 & Core diameter $(\mathrm{cm})$ & 180 \\
4 & Core height $(\mathrm{cm})$ & 197 \\
5 & Fuel material & $\mathrm{UO}_{2}$ \\
6 & Fuel type & Pebble \\
7 & Mass of heavy metals per pebble $(\mathrm{g})$ & 5 \\
8 & Number of TRISO particles per pebble & 8335 \\
9 & Enrichment of fresh fuel $(\%)$ & 17 \\
10 & Number of pebbles in the core under & 27000 \\
& equilibrium & \\
\hline
\end{tabular}

Analyses performed using ORIGEN2 computer code with its libraries modified for high temperature operation $[13,14]$. The results of core inventory calculation are shown in Table 3.

The data on RSG sourceterm was obtained from RSG-GAS SAR report [1]. The RSG-GAS sourceterm had been calculated under the assumption that the release of fission products from core due to uranium contaminant on the outer surface of the cladding. Uranium contaminants on the surface of the cladding can reach 10 microns of uranium weight [1]. The estimated sourceterm of the RSG-GAS is shown in Table 4.

The RDE sourceterm was calculated under the assumption that there are defects and impurities in the TRISO fuel because of the limitations of the fabrication. The mechanisms of fission products release from the fuel to the environment depend on on the safety features design of HTGR $[2,11,14,15]$. Sourceterm calculations were performed using the same mechanisms as previous studies [15], but with the assumptions of a more pessimistic release fraction. The result of modification calculation for RDE sourceterm has shown in Table 5.

\section{Meteorological data}

The data used in this work extracted from the meteorological station at KNS. The speed of wind was measured every $15 \mathrm{~min}$ and compiled to comprise a hourly average value. The wind directions were grouped into 16 sectors. The direction sectors used to classify meteorological data in accordance with Pasquill category scheme (meteorological data registered for a one-year period). The mathematical models used to get the generic data set in PC-CREAM 08 are atmospheric dispersion using a Gaussian plume model, dry deposition, and wet deposition. The dry deposition use a source depletion model, while the wet deposition use a washout coefficient approach. The Gaussian plume dispersion model was applied here to access the long-term atmospheric release. The model is widely accepted for use in radiological assessment [5,16,17]. The model is considered appropriate for representing the dispersion of either continual or long-term intermittent release $[5,16]$. The meteorological data used a uniform wind rose, $60 \%$ class D and $\mathrm{E}$ and $40 \%$ rain in $\mathrm{C}$ and D. The radiation dose was calculated based on the radionuclides in the sourceterm.

\section{Population distribution}

The individual dose calculation used consumption rate data for foodstuff. The collective doses calculation use population distribution within $5 \mathrm{~km}$ from KNS. The population distribution and agricultural products are represented around KNS within $5 \mathrm{~km}$ radius and 16 directions (sectors) as shown in Table 2. Table 2 presents the results obtained from data processing using a GIS program with data input as the digital map data combined with the BPS-2015 population data (BPS/Central Agency of Statistics).

Table 2. Population distribution within the radius of $5 \mathrm{~km}$ from RSG

\begin{tabular}{|c|c|c|c|c|c|c|c|}
\hline \multicolumn{8}{|c|}{ Population } \\
\hline \multirow[b]{2}{*}{ Sectors } & \multicolumn{7}{|c|}{ Distance radial from RSG $(\mathrm{km})$} \\
\hline & 0.3 & 0.5 & 1.0 & 2.0 & 3.0 & 4.0 & 5.0 \\
\hline 1 (North) & 85 & 170 & 511 & 1532 & 4720 & 11293 & 13059 \\
\hline 2 (NNE) & 85 & 170 & 511 & 2201 & 5425 & 5326 & 9103 \\
\hline $3(\mathrm{NE})$ & 85 & 170 & 511 & 1367 & 2466 & 4334 & 6879 \\
\hline 4 (ENE) & 85 & 170 & 511 & 1556 & 2490 & 3103 & 3535 \\
\hline 5 (East) & 46 & 92 & 276 & 884 & 1906 & 2784 & 2900 \\
\hline 6 (ESE) & 46 & 92 & 276 & 736 & 1308 & 3021 & 1708 \\
\hline 7 (SE) & 46 & 92 & 276 & 736 & 1640 & 1864 & 1994 \\
\hline 8 (SSE) & 46 & 92 & 276 & 954 & 1878 & 1818 & 648 \\
\hline 9 (Sourth) & 46 & 92 & 276 & 1054 & 1678 & 972 & 1650 \\
\hline $10(\mathrm{SSW})$ & 88 & 177 & 276 & 816 & 1126 & 2208 & 3277 \\
\hline $11(\mathrm{SW})$ & 85 & 170 & 347 & 724 & 1126 & 1448 & 2099 \\
\hline 12 (WSW) & 85 & 170 & 456 & 2242 & 2073 & 1659 & 1378 \\
\hline 13 (West) & 85 & 170 & 456 & 2573 & 4002 & 2623 & 3327 \\
\hline $14(\mathrm{WNW})$ & 85 & 170 & 912 & 2573 & 4002 & 4529 & 3597 \\
\hline $15(\mathrm{NW})$ & 85 & 170 & 511 & 2235 & 4207 & 4185 & 3523 \\
\hline $16(\mathrm{NNW})$ & 85 & 170 & 511 & 1559 & 2851 & 2060 & 3108 \\
\hline
\end{tabular}

\section{Spatial data}

The PC-CREAM 08 ingestion exposure pathways included for atmospheric dispersion are: 
(i) Consumption of cow and sheep meat and liver, (ii) Consumption of agricultural products as well as green vegetables, root vegetables, grains, and fruits, (iii) Consumption of dairy products like cow milk and its products.

Locally-produced food consumption was assumed to comprise $20 \%$ of the annual food intake for cow, sheep meat, and sheep liver, $80 \%$ for vegetable and fruit consumption, and $60 \%$ for grain products for the region inside $5 \mathrm{~km}$ radius around KNS. The individual doses at each sector was calculated based on the assumption that the individual's occupancy indoors is $90 \%$ within $0.5 \mathrm{~km}$ and $80 \%$ between $0.5 \mathrm{~km}$ and $5 \mathrm{~km}$.

\section{Dose calculation}

The dose calculation followed the Gaussian plume atmospheric model [5,8,17-19]. The critical group selected consisted of adults. The adults' groups were assumed to be the people who live $10 \%$ of their total living time outdoors within the distance of $0.5 \mathrm{~km}$, and those who live $20 \%$ of outdoors within a distance range of between 0.5 and $5 \mathrm{~km}$ from KNS.

\section{RESULTS AND DISCUSSION}

\section{Core inventory}

The results of the calculation of RDE inventory, based on the data in Table 1, are showed in Table 3.

Table 3. Reactor Inventory for RDE base on Geometry of HTR-10

\begin{tabular}{lclc}
\hline \multicolumn{1}{c}{ Nuclide } & Activity $(\mathrm{Bq})$ & Nuclide & Activity $(\mathrm{Bq})$ \\
\hline${ }^{3} \mathrm{H}$ & $3.94 \times 10^{12}$ & ${ }^{131} \mathrm{I}$ & $6.67 \times 10^{16}$ \\
${ }^{83 \mathrm{~m}} \mathrm{Kr}$ & $8.03 \times 10^{15}$ & ${ }^{132} \mathrm{I}$ & $9.62 \times 10^{16}$ \\
${ }^{85} \mathrm{Kr}$ & $1.15 \times 10^{14}$ & ${ }^{133} \mathrm{I}$ & $1.35 \times 10^{17}$ \\
${ }^{85 \mathrm{~m}} \mathrm{Kr}$ & $1.54 \times 10^{16}$ & ${ }^{134} \mathrm{I}$ & $1.48 \times 10^{17}$ \\
${ }^{87} \mathrm{Kr}$ & $2.91 \times 10^{16}$ & ${ }^{135} \mathrm{I}$ & $1.27 \times 10^{17}$ \\
${ }^{88} \mathrm{Kr}$ & $4.88 \times 10^{16}$ & ${ }^{89} \mathrm{Sr}$ & $5.06 \times 10^{16}$ \\
${ }^{131 \mathrm{~m}} \mathrm{Xe}$ & $1.06 \times 10^{14}$ & ${ }^{90} \mathrm{Sr}$ & $1.23 \times 10^{16}$ \\
${ }^{133 \mathrm{~m}} \mathrm{Xe}$ & $5.53 \times 10^{14}$ & ${ }^{134} \mathrm{Cs}$ & $8.63 \times 10^{15}$ \\
${ }^{133} \mathrm{Xe}$ & $1.36 \times 10^{17}$ & ${ }^{137} \mathrm{Cs}$ & $2.42 \times 10^{16}$ \\
${ }^{135 \mathrm{~m}} \mathrm{Xe}$ & $2.75 \times 10^{16}$ & ${ }^{110} \mathrm{Ag}$ & $2.75 \times 10^{16}$ \\
${ }^{135} \mathrm{Xe}$ & $7.80 \times 10^{16}$ & & \\
\hline
\end{tabular}

The calculation shows that the nuclides in RDE inventory can divided into groups, namely noble gases ( $\mathrm{Kr}$ and $\mathrm{Xe}$ ), halogen (I), $\mathrm{Cs}, \mathrm{Sr}, \mathrm{Ag}$, and ${ }^{3} \mathrm{H}$.

\section{Reactor sourceterm}

The reactor sourceterm for the RSG was taken from RSG-GAS SAR report [1] and is showed in Table 4. The calculation results for RDE sourceterm are showed in Table 5. Table 4 and Table 5 show that the RSG-GAS sourceterm is almost three times larger than the RDE sourceterm. Although they are of different types, that ratio is comparable to the ratio of the powers of the two reactors. Another similarity of the two reactors is the radionuclides that exhibit the highest activity. The highest activity was shown by the noble gas group, namely $\mathrm{Xe}$ and $\mathrm{Kr}$. Noble gases do not interact with any material, so they cannot be filtered by the filter system in the reactor.

Table 4. Sourceterm for the RSG [1]

\begin{tabular}{lllc}
\hline Nuclide & Activity $(\mathrm{Bq} / \mathrm{yr})$ & Nuclide & Activity $(\mathrm{Bq} / \mathrm{yr})$ \\
\hline${ }^{83 \mathrm{~m}} \mathrm{Kr}$ & $5.99 \times 10^{11}$ & ${ }^{131} \mathrm{I}$ & $5.33 \times 10^{7}$ \\
${ }^{85} \mathrm{Kr}$ & $5.70 \times 10^{6}$ & ${ }^{132} \mathrm{I}$ & $3.37 \times 10^{7}$ \\
${ }^{85 \mathrm{~m}} \mathrm{Kr}$ & $3.08 \times 10^{12}$ & ${ }^{133} \mathrm{I}$ & $2.00 \times 10^{8}$ \\
${ }^{88} \mathrm{Kr}$ & $8.70 \times 10^{12}$ & ${ }^{134} \mathrm{I}$ & $1.31 \times 10^{6}$ \\
${ }^{131 \mathrm{~m}} \mathrm{Xe}$ & $6.33 \times 10^{11}$ & ${ }^{135} \mathrm{I}$ & $2.09 \times 10^{8}$ \\
${ }^{133} \mathrm{Xe}$ & $3.64 \times 10^{12}$ & ${ }^{89} \mathrm{Sr}$ & $5.96 \times 10^{3}$ \\
${ }^{133 \mathrm{~m}} \mathrm{Xe}$ & $9.07 \times 10^{12}$ & ${ }^{90} \mathrm{Sr}$ & $3.66 \times 10^{1}$ \\
${ }^{135} \mathrm{Xe}$ & $1.92 \times 10^{12}$ & ${ }^{95} \mathrm{Zr}$ & $6.03 \times 10^{3}$ \\
${ }^{135 \mathrm{~m}} \mathrm{Xe}$ & $1.61 \times 10^{7}$ & ${ }^{95} \mathrm{Nb}$ & $1.18 \times 10^{4}$ \\
${ }^{138} \mathrm{Xe}$ & $1.54 \times 10^{7}$ & ${ }^{103} \mathrm{Ru}$ & $2.25 \times 10^{5}$ \\
${ }^{14} \mathrm{C}$ & $9.30 \times 10^{7}$ & ${ }^{41} \mathrm{Ar}$ & $3.00 \times 10^{11}$ \\
${ }^{3} \mathrm{H}$ & $7.90 \times 10^{10}$ & & \\
\hline
\end{tabular}

Table 5. Sourceterm for the RDE

\begin{tabular}{llll}
\hline Nuclide & Activity $(\mathrm{Bq} / \mathrm{yr})$ & Nuclide & Activity $(\mathrm{Bq} / \mathrm{yr})$ \\
\hline${ }^{3} \mathrm{H}$ & $1.91 \times 10^{10}$ & ${ }^{14} \mathrm{C}$ & $3.10 \times 10^{7}$ \\
${ }^{83 \mathrm{~m}} \mathrm{Kr}$ & $1.62 \times 10^{3}$ & ${ }^{131} \mathrm{I}$ & $1.12 \times 10^{5}$ \\
${ }^{85} \mathrm{Kr}$ & $7.05 \times 10^{10}$ & ${ }^{132} \mathrm{I}$ & $1.68 \times 10^{5}$ \\
${ }^{85 \mathrm{~m}} \mathrm{Kr}$ & $4.38 \times 10^{9}$ & ${ }^{133} \mathrm{I}$ & $2.43 \times 10^{5}$ \\
${ }^{87} \mathrm{Kr}$ & $1.80 \times 10^{11}$ & ${ }^{134} \mathrm{I}$ & $2.84 \times 10^{5}$ \\
${ }^{88} \mathrm{Kr}$ & $3.56 \times 10^{11}$ & ${ }^{135} \mathrm{I}$ & $1.96 \times 10^{5}$ \\
${ }^{131 \mathrm{~m}} \mathrm{Xe}$ & $5.35 \times 10^{9}$ & ${ }^{88} \mathrm{Rb}$ & $1.18 \times 10^{5}$ \\
${ }^{133} \mathrm{Xe}$ & $1.03 \times 10^{12}$ & ${ }^{89} \mathrm{Sr}$ & $1.52 \times 10^{5}$ \\
${ }^{133 m} \mathrm{Xe}$ & $2.95 \times 10^{10}$ & ${ }^{90} \mathrm{Sr}$ & $6.14 \times 10^{3}$ \\
${ }^{135} \mathrm{Xe}$ & $3.97 \times 10^{11}$ & ${ }^{134} \mathrm{Cs}$ & $3.58 \times 10^{3}$ \\
${ }^{135 m} \mathrm{Xe}$ & $1.32 \times 10^{11}$ & ${ }^{137} \mathrm{Cs}$ & $7.96 \times 10^{3}$ \\
${ }^{110} \mathrm{Ag}$ & $2.48 \times 10^{2}$ & & \\
\hline
\end{tabular}

\section{Individual dose}

The dose is calculated for the area within $5 \mathrm{~km}$ around KNS-1 and KNS-2 for eight different distances $(0.3,0.5,1,2,3,4$, and $5 \mathrm{~km})$ and 16 directions. The results of the calculation for the total individual dose for adult from the RSG-GAS for all pathways and nuclides are given in Table 6 . The trend of radiation dose in Table 6 shows that the individual dose decreases with increasing distance from the stack. The data in Table 6 also shows that the higher doses for all distances occurred in the South (S, sector 9 direction). The highest dose in KNS-1 from RSG-GAS is $9.31 \times 10^{-4} \mathrm{mSv} / \mathrm{yr}$. Nevertheless, the doses do not exceed the constraint of the dose constraint of $0.3 \mathrm{mSv} / \mathrm{yr}$ set by BAPETEN. 
The estimated dose from the RDE is shown in Table 7. The highest dose in KNS-2 from the RDE is $4.17 \times 10^{-4} \mathrm{mSv} / \mathrm{yr}$. The radiation dose from RDE operation is less than the dose of RSG-GAS operation, proportional to the sourceterm data in Table 4 and Table 5. The doses do not exceed the dose constraint of $0.3 \mathrm{mSv} / \mathrm{y}$ set by BAPETEN.

From the calculation of the dose received by the public from the simultaneous operation of both the RDE and RSG-GAS reactors, the dose of the two reactors is compiled. The radiation doses of sums stack (RSG-GAS and RDE) are shown in Table 8 . Table 8 shows that the highest dose was $6.16 \times 10^{-3} \mathrm{mSv} / \mathrm{y}$, still below the dose constraint of $0.3 \mathrm{mSv} / \mathrm{y}$. This shows that the RDE in KNS-2 does not add significantly to the acceptance radiation dose in the environment in KNS-1.

Comparison of radiation dose in the KNS-1 before and after the operation of the RDE shows that the dose of radiation in whole KNS still do not exceed the dose constraint. It is caused by the power of the RDE being only one-third of the power of the already-existing RSG-GAS. Additionally, the RDE is a HTGR reactor that produces very small amount of radioactive releases. This is clear from the sourceterm between the two reactors as shown in Table 4 and Table 5.
Depending on the pathway, radiation doses from plume (gamma and beta) tends to be higher than from ground surface. This is since humans are directly exposed to the radiation originated from the plume, while the radiation that comes from the ground still has to pass through various mechanisms, such as ground water transportation, direct absorption, and by absorption through plants. Figure 2 shows the percentage of contributions of the different pathways to total individual dose in the $\mathrm{S}$ direction for various distances within $5 \mathrm{~km}$.

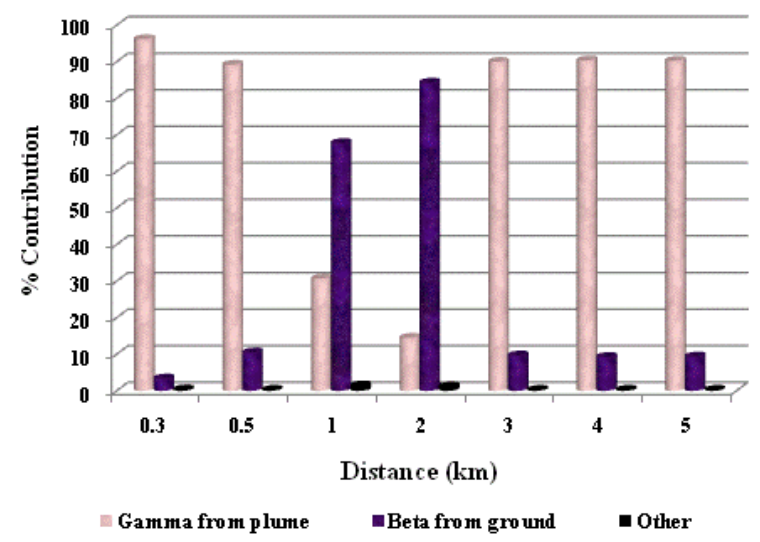

Fig. 2. Different pathway percentages for atmospheric dispersion.

Table 6. Total individual dose for adult (all pathways and nuclides) from RSG

\begin{tabular}{|c|c|c|c|c|c|c|c|}
\hline \multicolumn{8}{|c|}{ Total individual dose for adults (all pathways and nuclides), $\mathrm{mSv} / \mathrm{yr}$} \\
\hline \multirow[t]{2}{*}{ Sectors } & \multicolumn{7}{|c|}{ Radial distance $(\mathrm{km})$ from RSG } \\
\hline & 0.3 & 0.5 & 1.0 & 2.0 & 3.0 & 4.0 & 5.0 \\
\hline 1 (North) & $1.76 \times 10^{-5}$ & $1.52 \times 10^{-5}$ & $2.74 \times 10^{-5}$ & $4.62 \times 10^{-5}$ & $4.70 \times 10^{-5}$ & $4.19 \times 10^{-5}$ & $3.71 \times 10^{-5}$ \\
\hline 2 (NNE) & $1.20 \times 10^{-4}$ & $1.28 \times 10^{-4}$ & $9.55 \times 10^{-5}$ & $6.35 \times 10^{-5}$ & $5.93 \times 10^{-5}$ & $5.44 \times 10^{-5}$ & $4.74 \times 10^{-5}$ \\
\hline $3(\mathrm{NE})$ & $1.20 \times 10^{-4}$ & $1.32 \times 10^{-4}$ & $9.55 \times 10^{-5}$ & $6.35 \times 10^{-5}$ & $5.93 \times 10^{-5}$ & $5.44 \times 10^{-5}$ & $4.74 \times 10^{-5}$ \\
\hline 4 (ENE) & $1.21 \times 10^{-4}$ & $1.07 \times 10^{-4}$ & $7.96 \times 10^{-5}$ & $5.24 \times 10^{-5}$ & $4.35 \times 10^{-5}$ & $3.47 \times 10^{-5}$ & $2.39 \times 10^{-5}$ \\
\hline 5 (East) & $3.92 \times 10^{-4}$ & $3.84 \times 10^{-4}$ & $3.87 \times 10^{-4}$ & $3.35 \times 10^{-4}$ & $2.63 \times 10^{-4}$ & $2.05 \times 10^{-4}$ & $2.05 \times 10^{-4}$ \\
\hline 6 (ESE) & $1.06 \times 10^{-4}$ & $2.86 \times 10^{-4}$ & $1.24 \times 10^{-4}$ & $1.96 \times 10^{-4}$ & $1.86 \times 10^{-4}$ & $6.62 \times 10^{-5}$ & $7.13 \times 10^{-5}$ \\
\hline 7 (SE) & $3.79 \times 10^{-4}$ & $4.20 \times 10^{-4}$ & $1.24 \times 10^{-4}$ & $1.96 \times 10^{-4}$ & $1.86 \times 10^{-4}$ & $6.62 \times 10^{-5}$ & $7.13 \times 10^{-5}$ \\
\hline 8 (SSE) & $4.84 \times 10^{-4}$ & $6.00 \times 10^{-4}$ & $3.09 \times 10^{-4}$ & $2.24 \times 10^{-4}$ & $1.22 \times 10^{-4}$ & $1.55 \times 10^{-4}$ & $9.73 \times 10^{-5}$ \\
\hline 9 (South) & $9.31 \times 10^{-4}$ & $6.40 \times 10^{-4}$ & $7.43 \times 10^{-4}$ & $4.29 \times 10^{-4}$ & $1.22 \times 10^{-4}$ & $2.08 \times 10^{-4}$ & $1.99 \times 10^{-4}$ \\
\hline $10(\mathrm{SSW})$ & $9.31 \times 10^{-4}$ & $5.58 \times 10^{-4}$ & $5.11 \times 10^{-4}$ & $3.87 \times 10^{-4}$ & $1.60 \times 10^{-4}$ & $1.57 \times 10^{-4}$ & $2.51 \times 10^{-5}$ \\
\hline 11 (SW) & $7.81 \times 10^{-4}$ & $3.79 \times 10^{-4}$ & $2.05 \times 10^{-4}$ & $1.61 \times 10^{-4}$ & $1.57 \times 10^{-4}$ & $1.34 \times 10^{-4}$ & $9.96 \times 10^{-6}$ \\
\hline 12 (WSW) & $7.43 \times 10^{-4}$ & $6.13 \times 10^{-4}$ & $2.32 \times 10^{-4}$ & $1.16 \times 10^{-4}$ & $2.51 \times 10^{-5}$ & $1.34 \times 10^{-4}$ & $2.05 \times 10^{-4}$ \\
\hline $13(\mathrm{~h}$ & $6.13 \times 10^{-4}$ & $4.84 \times 10^{-4}$ & $3.35 \times 10^{-4}$ & $1.16 \times 10^{-4}$ & $2.52 \times 10^{-6}$ & $2.46 \times 10^{-6}$ & $2.78 \times 10^{-6}$ \\
\hline $14(\mathrm{~V}$ & $2.24 \times 10^{-4}$ & $4.29 \times 10^{-4}$ & $2.97 \times 10^{-6}$ & $4.02 \times 10^{-6}$ & $2.90 \times 10^{-6}$ & $2.24 \times 10^{-6}$ & $2.23 \times 10^{-6}$ \\
\hline $15(\mathrm{~N}$ & $1.62 \times 10^{-4}$ & $9.40 \times 10^{-5}$ & $8.39 \times 10^{-5}$ & $7.43 \times 10^{-5}$ & $3.53 \times 10^{-5}$ & $9.09 \times 10^{-6}$ & $2.02 \times 10^{-6}$ \\
\hline $16(\mathrm{NNW})$ & $1.62 \times 10^{-4}$ & $7.87 \times 10^{-5}$ & $8.58 \times 10^{-5}$ & $7.57 \times 10^{-5}$ & $3.69 \times 10^{-5}$ & $8.93 \times 10^{-6}$ & $8.26 \times 10^{-6}$ \\
\hline
\end{tabular}

Table 7. Total Individual dose for adult (all pathways and nuclides) from RDE

\begin{tabular}{|c|c|c|c|c|c|c|c|}
\hline \multicolumn{8}{|c|}{ Total individual dosefor adults (all pathways and nuclides), mSv/yr } \\
\hline \multirow[t]{2}{*}{ Sectors } & \multicolumn{7}{|c|}{ Radial distance $(\mathrm{km})$ from RDE } \\
\hline & 0.3 & 0.5 & 1.0 & 2.0 & 3.0 & 4.0 & 5.0 \\
\hline No & $8.26 \times 10$ & $.51 \times 10^{-6}$ & $1.94 \times 10^{-6}$ & $2.05 \times 10^{-6}$ & $8.08 \times 10^{-5}$ & $6.09 \times 10^{-5}$ & $1.12 \times 10^{-5}$ \\
\hline$(\mathrm{N}$ & $8.26 x$ & $1.51 \times 10^{-6}$ & $1.93 \times 10^{-6}$ & $2.06 \times 10^{-6}$ & $1.93 \times 10^{-5}$ & $8.00 \times 10^{-5}$ & $1.12 \times 10^{-5}$ \\
\hline E) & $7.65 x$ & $2.40 \times$ & $2.31 \times$ & & $1.93 \times$ & & $1.12 \times 10^{-5}$ \\
\hline JE) & 1.91 & $2.39 \times$ & $2.31 \times$ & & $1.37 \times 10^{-5}$ & $0^{-6}$ & $6.29 \times 10^{-6}$ \\
\hline & $2.62 x$ & $2.18 x$ & $1.19 x$ & $1.73 \times 10^{-5}$ & $3.98 \times 10^{-5}$ & $5.33\rangle$ & $6.03 x$ \\
\hline & 3.7 & 3.75 & $3.54>$ & $3.70 \times$ & $5.57 \times 10^{-5}$ & $6.91 \times 10^{-6}$ & 6.62 \\
\hline & 3. & $3.75 \times$ & $3.54 \times$ & $3.70 x$ & 5.5 & $7.56 x$ & 6.6 \\
\hline & $2.17 x$ & $2.05 x$ & 1.78 & 1.0 & 1.7 & 3.7 & 2.0 \\
\hline & $4.12 x$ & $4.17 x$ & 3.83 & $3.49 x$ & 3.18 & 1.39 & 1.3 \\
\hline & $2.41 x$ & $2.14 \times$ & $1.30 x$ & $1.28 x$ & 3.9 & $8.93 x$ & 8.2 \\
\hline & $2.41 \times$ & $2.14 \times$ & $1.30 x$ & $1.28 x$ & $7.95 x$ & $2.46 x$ & 2.7 \\
\hline & $2.71 \times$ & $2.68 \times 10^{-4}$ & $2.65 \times 10^{-4}$ & $1.77 \times 10^{-4}$ & $5.49 \times 10^{-5}$ & $1.25 \times 10^{-5}$ & 4.02 \\
\hline & $3.92 x$ & $3.84 \times 10^{-4}$ & $3.87 \times 10^{-4}$ & $2.63 \times 10^{-4}$ & $3.05 \times 10^{-5}$ & $3.18 \times 10^{-5}$ & $5.56 \times 10^{-5}$ \\
\hline & $1.06 x$ & 6.87 & 6.91 & 6.25 & 2.64 & 1.2 & 1. \\
\hline & $2.67 x$ & $4.09 x$ & $2.97 \times$ & $2.90 x$ & 2.24 & $2.23 x$ & 7.1 \\
\hline & $67 \times$ & $4.09 \times 1$ & $1.94 \times 10^{-6}$ & $1.95 x$ & $1.91 \times$ & $1.64 \times 10^{-6}$ & 8.8 \\
\hline
\end{tabular}


Table 8. Total individual dosefor adult (all pathways and nuclides) of sum stacks (RSG and RDE)

\begin{tabular}{|c|c|c|c|c|c|c|c|}
\hline \multicolumn{8}{|c|}{ Total individual dose for adults of sum stacks (all pathways and nuclides), $\mathrm{mSv} / \mathrm{yr}$} \\
\hline \multirow[t]{2}{*}{ Sectors } & \multicolumn{7}{|c|}{ Radial distance $(\mathrm{km})$ from RSG } \\
\hline & 0.3 & 0.5 & 1.0 & 2.0 & 3.0 & 4. & .0 \\
\hline orth) & $.12 \times 1$ & 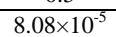 & $\overline{99 \times 11}$ & $34 \times 10^{-5}$ & $2.98 \times 10^{-5}$ & $1.93 \times 10^{-5}$ & $1.74 \times 10$ \\
\hline & $3.06 \times 10^{-4}$ & $1 \times 10^{-4}$ & $6.72 \times 10^{-5}$ & 6.32 & $5.71 \times 10^{-5}$ & $5.05 \times 10^{-5}$ & $4.15 \times 10^{-5}$ \\
\hline & & $2.93 \times 10^{-4}$ & $2.99 \times 10^{-4}$ & $6.71 \times 10^{-5}$ & $6.40 \times 10^{-5}$ & $86 \times 10^{-5}$ & \\
\hline & & & & & & & \\
\hline & & & & & & & \\
\hline & 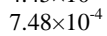 & 5.5 & 1.83 & 1.81 & $1.77 \times 10^{-4}$ & 1.39 & 4.1 \\
\hline & & & & & & & \\
\hline 8 (SSE & & 9.24 & 7.1 & & $6.24 x$ & $10^{-4}$ & \\
\hline & & & & & & & \\
\hline & & & & & & & \\
\hline 11 (s & $3.30 \times 10^{-4}$ & $2.94 \times$ & $1.87 \times 10^{-4}$ & $2.28 \times 10^{-4}$ & $2.15 \times 10^{-4}$ & $2.09 \times 10^{-4}$ & $1.65 \times 10^{-4}$ \\
\hline & $1.45 \times 10^{-4}$ & 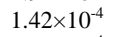 & & $2.46 \times 10^{-4}$ & $1.38 \times 10^{-4}$ & & \\
\hline & & & & & & & \\
\hline & $3.41 \times 10^{-4}$ & 2.14 & $2.13 x$ & $5.56 x$ & $3.69 x$ & $3.71 \times 10^{-5}$ & 3.18 \\
\hline & $2.67 \times 10^{-4}$ & $2.14 x$ & $2.13 x$ & $5.56 x$ & $3.69 x$ & $3.71 \times$ & 3.18 \\
\hline 16 (NNW) & $1.36 \times 10^{-4}$ & $1.40 \times 10^{-4}$ & $7.87 \times 10^{-5}$ & $4.84 \times 10^{-5}$ & $2.98 \times 10^{-5}$ & $1.93 \times 10^{-5}$ & $6.29 \times 10^{-6}$ \\
\hline
\end{tabular}

Figure 2 shows that for the area within $500 \mathrm{~m}$ radius and between $3 \mathrm{~km}$ and $5 \mathrm{~km}$, about $90 \%$ of individual doses are from external sources. The external dose is due to gamma radiation from the airborne radionuclides. It is also shown that for the area between $500 \mathrm{~m}$ and $2 \mathrm{~km}, 90 \%$ of beta radiation comes from the deposited beta radionuclides in the ground. The approximately $2 \%$ remaining doses is related to other pathways. For the radius of $500 \mathrm{~m}$ in the $\mathrm{S}$ direction, the percentage of the total individual dose due to different nuclides is shown on in Fig. 3.

Noble gas nuclides such as $\mathrm{Kr}, \mathrm{Xe}$, and $\mathrm{Ar}$ contributed higher radiation doses than other nuclides. This dose is in accordance with the amount of sourceterm in Tables 4 and 5, is also comparable to that of gamma pathway from the plume.

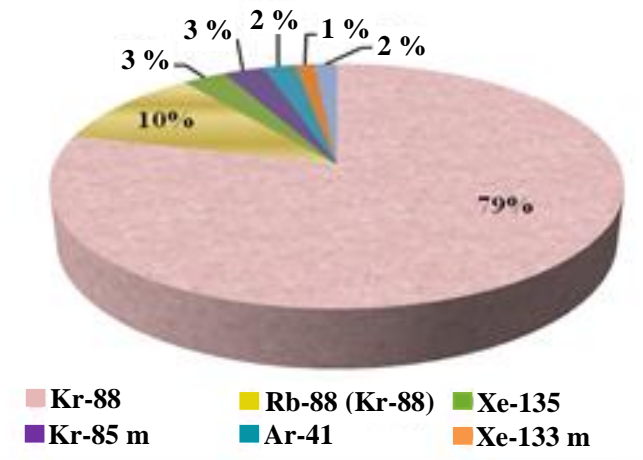

Fig. 3. Percentages of different nuclides for atmospheric dispersion in the $\mathrm{S}$ direction within $500 \mathrm{~m}$.

\section{Collective dose}

The calculated total collective dose within $5 \mathrm{~km}$ radius is shown in Table 9. The given total collective dose is for all pathways and nuclides from sum stacks (RSG-GAS and RDE). The highest calculated total collective dose is $6.37 \times 10^{-3}$ man-Sv/yr. The important pathways for the dose acceptance rate were gamma radiation from the cloud-plume in the area within $500 \mathrm{~m}$ and beta radiation from ground in the area between area $3 \mathrm{~km}$ and $5 \mathrm{~km}$.

The calculations for individual and collective doses via atmospheric discharge showed that dominant radionuclides for external and internal exposure from noble gases ( $\mathrm{Kr}, \mathrm{Xe}$, and $\mathrm{Ar}$ ).

Table 9. Collective dose for all pathways and nuclides of sum stacks (RSG-GAS and RDE)

\begin{tabular}{|c|c|c|c|c|c|c|c|}
\hline \multirow{3}{*}{ Sector } & \multicolumn{7}{|c|}{ Collective dose man-Sv/yr } \\
\hline & \multicolumn{7}{|c|}{ Radial distance $(\mathrm{km})$ from RSG-GAS } \\
\hline & 0.3 & 0.5 & 1 & 2 & 3 & 4 & 5 \\
\hline 1 (North) & $9.52 \times 10^{-6}$ & $1.37 \times 10^{-5}$ & $3.11 \times 10^{-5}$ & $7.41 \times 10^{-5}$ & $1.41 \times 10^{-4}$ & $2.18 \times 10^{-4}$ & $2.27 \times 10^{-4}$ \\
\hline $2(\mathrm{NNE})$ & $2.60 \times 10^{-5}$ & $5.29 \times 10^{-5}$ & $3.43 \times 10^{-5}$ & $1.39 \times 10^{-4}$ & $3.10 \times 10^{-4}$ & $2.69 \times 10^{-4}$ & $3.78 \times 10^{-5}$ \\
\hline $3(\mathrm{NE})$ & $2.13 \times 10^{-5}$ & $4.98 \times 10^{-5}$ & $1.53 \times 10^{-4}$ & $9.17 \times 10^{-5}$ & $1.58 \times 10^{-4}$ & $2.54 \times 10^{-4}$ & $3.50 \times 10^{-4}$ \\
\hline 4 (ENE) & $1.85 \times 10^{-5}$ & $3.57 \times 10^{-5}$ & $8.69 \times 10^{-5}$ & $2.43 \times 10^{-4}$ & $1.41 \times 10^{-4}$ & $1.27 \times 10^{-4}$ & $9.58 \times 10^{-5}$ \\
\hline 5 (East) & $2.05 \times 10^{-5}$ & $3.94 \times 10^{-5}$ & $4.58 \times 10^{-5}$ & $1.46 \times 10^{-4}$ & $4.84 \times 10^{-5}$ & $5.18 \times 10^{-5}$ & $3.94 \times 10^{-5}$ \\
\hline 6 (ESE) & $3.44 \times 10^{-5}$ & $5.07 \times 10^{-5}$ & $5.05 \times 10^{-5}$ & $1.33 \times 10^{-4}$ & $2.32 \times 10^{-4}$ & $4.20 \times 10^{-4}$ & $7.07 \times 10^{-5}$ \\
\hline 7 (SE) & $3.72 \times 10^{-5}$ & $6.21 \times 10^{-5}$ & $7.37 \times 10^{-5}$ & $1.46 \times 10^{-4}$ & $2.23 \times 10^{-4}$ & $7.27 \times 10^{-5}$ & $7.56 \times 10^{-5}$ \\
\hline 8 (SSE) & $4.57 \times 10^{-5}$ & $8.50 \times 10^{-5}$ & $1.98 \times 10^{-4}$ & $6.43 \times 10^{-4}$ & $1.17 \times 10^{-3}$ & $7.94 \times 10^{-4}$ & $1.60 \times 10^{-4}$ \\
\hline 9 (South) & $2.83 \times 10^{-4}$ & $5.37 \times 10^{-4}$ & $4.06 \times 10^{-4}$ & $1.20 \times 10^{-3}$ & $1.62 \times 10^{-3}$ & $7.56 \times 10^{-4}$ & $1.16 \times 10^{-3}$ \\
\hline $10(\mathrm{SSW})$ & $1.16 \times 10^{-4}$ & $2.11 \times 10^{-4}$ & $3.12 \times 10^{-4}$ & $7.48 \times 10^{-4}$ & $1.00 \times 10^{-3}$ & $1.75 \times 10^{-3}$ & $1.39 \times 10^{-3}$ \\
\hline $11(\mathrm{SW})$ & $2.81 \times 10^{-5}$ & $5.00 \times 10^{-6}$ & $6.49 \times 10^{-5}$ & $1.65 \times 10^{-4}$ & $2.42 \times 10^{-4}$ & $3.03 \times 10^{-4}$ & $3.46 \times 10^{-4}$ \\
\hline 12 (WSW) & $1.23 \times 10^{-5}$ & $2.41 \times 10^{-5}$ & $8.71 \times 10^{-5}$ & $5.52 \times 10^{-4}$ & $2.86 \times 10^{-4}$ & $9.21 \times 10^{-5}$ & $5.70 \times 10^{-5}$ \\
\hline 13 (West) & $2.90 \times 10^{-5}$ & $5.42 \times 10^{-5}$ & $1.23 \times 10^{-4}$ & $2.88 \times 10^{-4}$ & $4.08 \times 10^{-4}$ & $1.08 \times 10^{-4}$ & $1.36 \times 10^{-4}$ \\
\hline 14 (WNW) & $2.90 \times 10^{-5}$ & $3.64 \times 10^{-5}$ & $1.94 \times 10^{-4}$ & $1.43 \times 10^{-4}$ & $1.48 \times 10^{-4}$ & $1.68 \times 10^{-4}$ & $1.14 \times 10^{-4}$ \\
\hline $15(\mathrm{NW})$ & $2.27 \times 10^{-5}$ & $3.64 \times 10^{-5}$ & $1.09 \times 10^{-4}$ & $1.24 \times 10^{-4}$ & $1.55 \times 10^{-4}$ & $1.55 \times 10^{-4}$ & $1.12 \times 10^{-4}$ \\
\hline 16 (NNW) & $1.16 \times 10^{-5}$ & $2.38 \times 10^{-5}$ & $4.02 \times 10^{-5}$ & $7.55 \times 10^{-5}$ & $8.50 \times 10^{-5}$ & $3.98 \times 10^{-5}$ & $1.95 \times 10^{-5}$ \\
\hline Total & $7.45 \times 10^{-4}$ & $1.32 \times 10^{-3}$ & $2.01 \times 10^{-3}$ & $4.91 \times 10^{-3}$ & $6.37 \times 10^{-3}$ & $5.58 \times 10^{-3}$ & $4.73 \times 10^{-3}$ \\
\hline
\end{tabular}

\section{CONCLUSION}

The expected radiation dose due to the normal operation of RSG-GAS and RDE by atmospheric dispersion approach for adults is $6.16 \times 10^{-3} \mathrm{mSv} / \mathrm{y}$ in $\mathrm{S}$ direction and $300 \mathrm{~m}$ distance from the RSG-GAS The operation of the RDE in KNS-2 does not add significantly to acceptance radiation dose in the environment in KNS-1. It can also be concluded that the estimated effective doses are lower than the dose constraint of $0.3 \mathrm{mSv} / \mathrm{y}$ associated with this plant.

\section{ACKNOWLEDGMENT}

The authors would like to express their gratitude to DIPA PTKRN (Center for Nuclear Reactor Technology and Safety) 2015-2016, who funded and supported this study. 


\section{REFERENCES}

1. Anonymous, Safety Analysis Report SARRSG, BATAN (2009).

2. J.D. Hales, R.L. Williamson, S.R. Novascone et al., J. Nucl. Mater. 443 (2013) 531.

3. Y. Katoh, G. Vasudevamurthy, T. Nozawa et al., J. Nucl. Mater. 441 (2013) 718.

4. J.A. Phillips, S.G. Nagley and E.L. Shaber, J. Nucl. Eng. Des. 251 (2012) 261.

5. I. Korsakissok, A. Mathieu and D. Didier, Atmos. Environ. 70 (2013) 267.

6. G. Katata, M. Ota, H. Terada et al., J. Environ. Radioact. 109 (2012) 103.

7. H. Vandenhove, L. Sweeck, J.V. Batlle et al., J. Environ. Radioact. 126 (2013) 61.

8. S.A. Birikorang, R.G. Abrefah and R.B.M. Sogbadji, Progress in Nuclear Energy 79 (2015) 96.

9. Y. Katoh, L.L. Snead, C.H. Henager Jr. et al.,
10. L.Q. Zhang, C.H. Zhang, L.H. Han et al., J. Nucl. Mater. 455 (2014) 704.

11. Y. Katoh, K. Ozawa, C. Shih et al., J. Nucl. Mater. 448 (2014) 448.

12. J.L. Muswema, G.B. Ekoko, V.M. Lukanda et al., J. Nucl. Eng. Des. 281 (2015) 51.

13. M. Sohrabi, Z. Parsouzi, R. Amrollahi, Ann. Nucl. Energy 55 (2013) 351.

14. S. Kuntjoro and P.M. Udiyani, J. Urania 22 (2016) 53. (In Indonesia)

15. P.M. Udiyani and S. Kuntjoro, J. Urania 23 (2017) 45.

16. P. Pecha and E. Pechova, J. Atmos. Environ. 89 (2014) 298.

17. T.H. Woo, Ann. Nucl. Energy 53 (2013) 197.

18. Á. Leelkossy, R. Mészáros, I. Lagzi, J. Environ. Radioact. 102 (2011) 1117.

19. P.M. Udiyani, S. Kuntjoro, S. Widodo, Atom Indonesia 42 (2016) 63. 